\title{
Korormicin, a Novel Antibiotic Specifically Active against Marine Gram-negative Bacteria, Produced by a Marine Bacterium
}

\author{
Kazuhiro Yoshikawa, * TaKahide Takadera, Kyoko Adachi, \\ Miyuki Nishijima and Hiroshi Sano ${ }^{\dagger}$ \\ Shimizu Laboratories, Marine Biotechnology Institute Co. Ltd., \\ Shimizu, Shizuoka 424, Japan
}

(Received for publication July 31, 1997)

\begin{abstract}
A novel antibiotic named korormıcin was isolated from the marine bacterium, Pseudoalteromonas sp. F-420. This strain was isolated from the surface of a macro alga Halimeda sp. collected from Palau (the Republic of Belau). The planar structure of korormicin was determined by the result of 2D NMR studies and mass spectral data. Korormicin had specific inhibitory activity against marine Gram-negative bacteria, but was inactive against terrestrial microorganisms.
\end{abstract}

A growing number of natural products from marine organisms have recently been reported ${ }^{1)}$ and many of these compounds have shown interesting chemical and biological properties. As a promising source of biologically active compounds, we are focusing on marine bacteria and their products.

A screening for the antibacterial compounds produced by marine bacteria indicated that the culture broth of bacterial strain F-420, which had been obtained from the surface of a seaweed in Palau (the Republic of Belau), showed a unique antibacterial spectrum. It had inhibitory activity against such marine bacteria as Salinivibrio costicola ATCC $33508,{ }^{2)}$ but it did not affect the growth of terrestrial species at all. In the present paper, we describe the result of the taxonomical studies on the producing organism, F-420, and the fermentation, isolation, structural determination and biological properties of a novel antibiotic, named korormicin.

\section{Materials and Methods}

\section{General}

A cell suspension in aqueous ethanol was disrupted with a Branson 250 sonifier, and Merck silica gel 60 (230 400 mesh) was used for column chromatography. HPLC separation was performed by a TOSOH CCPM system with a UV 8010 tunable absorbance detector and was monitored at $254 \mathrm{~nm}$. FAB-MS was recorded with a JEOL JMS-SX102 mass spectrometer. ${ }^{1} \mathrm{H}$ - and ${ }^{13} \mathrm{C}$ NMR spectra were measured with a Varian Unity 500 NMR spectrometer, while the IR spectrum was obtained from a $\mathrm{KBr}$ pellet with a JASCO FT-IR 7000 spectrophotometer. Optical rotation was determined by a Horiba SEPA-300 polarimeter at ambient temperature.

\section{Producing Organism}

Korormicin producing bacterium F-420 was separated from the surface of a fresh macro alga of the Halimeda sp. collected from a shallow water off Koror in the Republic of Belau in July 1995. The bacterium was isolated on a 1/10MA plate prepared with tenth-strength Marine Broth 2216 (Difco, Detroit, MI, U.S.A.) and agar $1.5 \%$ in $75 \%$ of sea water. ${ }^{3)}$ The isolated strain was kept as frozen stock with $10 \%(\mathrm{v} / \mathrm{v})$ glycerol. Conventional taxonomical features were determined according to the procedures described by COWAN and STEEL, ${ }^{4)}$ except that all the media used were supplemented with $3 \% \mathrm{NaCl}$ or prepared in $75 \%$ artificial seawater (Tropic Marin, Aquarientechnik, Germany), because strain $\mathrm{F}-420$ required $\mathrm{NaCl}$ for growth. The change in $\mathrm{pH}$ value during the $\mathrm{O} / \mathrm{F}$ test was monitored by phenol red, and the $\mathrm{G}+\mathrm{C}$ content of bacterial DNA was determined by HPLC with a catalytic reaction using nuclease $\mathrm{P} 1 .^{5)} \mathrm{A}$ morphological study was carried out mainly by transmission electron microscopy. The isoprenoid quinone composition of strain $\mathrm{F}-420$ was analyzed according to the method of NisHiJme et al., ${ }^{6)}$ and identification was basically made according to BERGEY's Manual of Systematic Bacteriology. ${ }^{7)}$

Fermentation and Isolation of Korormicin

Pseudoalteromonas sp. F-420 was cultured in a 1-liter

+ Present Address: Kyowa Hakko Kogyo Co., Ltd., 1-6-1 Otemachı, Chiyoda-ku, Tokyo 100, Japan. 
Erlenmeyer flask containing $200 \mathrm{ml}$ of Marine Broth 2216. Cells collected by centrifugation were extracted with aqueous ethanol by using an ultrasonic cell disrupter. The concentrates of the ethanol solution was extracted twice with ethyl acetate, and the extract was then separated in a silica gel column by eluting with chloroform. The resulting active fraction was further purified by size-exclusion HPLC to give pure korormicin.

\section{Antimicrobial Susceptibility Test}

The antimicrobial activity of korormicin against marine and terrestrial bacteria on a Marine Agar (Difco) plate was tested by the paper disk method. Korormicin was dissolved in methanol at concentrations of 1000 $0.4 \mu \mathrm{g} / \mathrm{ml}$, and $50 \mu \mathrm{l}$ of the antibiotic solution was applied to a disk $8 \mathrm{~mm}$ in diameter. All bacteria were incubated at $30^{\circ} \mathrm{C}$ except for Escherichia coli and Bacillus subtilis strains which were incubated at $37^{\circ} \mathrm{C}$.

\section{Results and Discussion}

Taxonomical Studies

Strain F-420, a korormicin-producing bacterium, was subjected to the standard biological and physiological tests, the results being summarized in Table 1. The colony was circular, white in color pigmented yellow at the center when grown on a Marine Agar plate. It was of a Gram-negative aerobic rod and was motile by a polar flagellum. It grew in a temperature range of $10 \sim 50^{\circ} \mathrm{C}$ and required a $1 \sim 10 \% \mathrm{NaCl}$ concentration. The catalase and oxidase tests were positive, and the $\mathrm{O} / \mathrm{F}$ test was oxidative. Hydrolysis of DNA and liquefaction of gelatin were both positive. The $\mathrm{G}+\mathrm{C}$ content of DNA was $42.3 \mathrm{~mol} \%$, and the bacterium produced ubiquinone8 as the major isoprenoid quinone. According to the literature, ${ }^{7,8)}$ these results indicate that this strain could be classified as Pseudoalteromonas sp. Strain F-420 has been deposited at the National Institute of Bioscience and Human-Technology, Agency of Industrial Science and Technology, Ministry of International Trade and Industry, Tsukuba-shi, Japan, with the accession number FERM P-16084.

Fermentation and Isolation of Korormicin

A well-grown seed culture $(20 \mathrm{ml})$ of strain F-420 in marine broth was used to inoculate a $180-\mathrm{ml}$ medium in a 1-liter Erlenmeyer flask and was cultured at $30^{\circ} \mathrm{C}$ on a rotary shaker $(120 \mathrm{rpm})$ for 24 hours. The resulting

Table 1. Biological and physiological characteristics of strain F-420.

\begin{tabular}{|c|c|c|c|c|}
\hline Shape & \multicolumn{2}{|c|}{ Rod } & Production of: & \\
\hline Size & \multicolumn{2}{|c|}{$1.5 \sim 2.6 \times 0.6 \sim 1.2 \mu \mathrm{m}$} & Indole & - \\
\hline Cell pleomorphism & \multicolumn{2}{|c|}{-} & Hydrogen sulfide & - \\
\hline Motility & \multicolumn{2}{|l|}{+} & Gas from sugars & - \\
\hline Flagellation & \multicolumn{2}{|l|}{ Polar } & Hydrolysis of: & \\
\hline Spore formation & \multicolumn{2}{|l|}{-} & Starch & + \\
\hline Gram stain & \multicolumn{2}{|l|}{-} & Esculin & + \\
\hline Acid-fast & \multicolumn{2}{|l|}{-} & $\begin{array}{l}\text { DNA } \\
\text { Gelatin }\end{array}$ & $\begin{array}{l}+ \\
+\end{array}$ \\
\hline $\mathrm{O} / \mathrm{F}$ test & \multicolumn{2}{|c|}{ Oxidative } & Arginine & - \\
\hline Nitrate reduction & \multicolumn{2}{|c|}{-} & Utilization of: & \\
\hline MR test & \multicolumn{2}{|l|}{-} & Citrate & - \\
\hline VP test & \multicolumn{2}{|c|}{-} & L-Arabinose & - \\
\hline Pigmentation & \multicolumn{2}{|c|}{ Yellow (water-insoluble) } & D-Xylose & - \\
\hline Aerobic growth & \multicolumn{2}{|c|}{+} & D-Glucose & + \\
\hline Anaerobic growth & \multicolumn{2}{|l|}{-} & D-Mannose & + \\
\hline Urease & \multicolumn{2}{|l|}{-} & D-Fructose & + \\
\hline Oxidase & \multicolumn{2}{|l|}{+} & D-Galactose & - \\
\hline Catalase & \multicolumn{2}{|l|}{+} & Maltose & + \\
\hline \multirow[t]{2}{*}{$\beta$-Galactosidase } & \multirow{2}{*}{\multicolumn{2}{|c|}{-}} & Sucrose & - \\
\hline & & & Lactose & - \\
\hline \multirow{2}{*}{\multicolumn{2}{|c|}{$\begin{array}{l}\text { Temperature range for growth } \\
\text { Optimum growth temperature }\end{array}$}} & $10 \sim 50^{\circ} \mathrm{C}$ & Trehalose & + \\
\hline & & $24 \sim 38^{\circ} \mathrm{C}$ & D-Sorbitol & - \\
\hline \multicolumn{2}{|c|}{ pH range for growth } & $3 \sim 11$ & D-Mannitol & - \\
\hline \multicolumn{2}{|l|}{ Optimum growth $\mathrm{pH}$} & $6 \sim 10$ & Inositol & - \\
\hline \multicolumn{2}{|l|}{ Salt requirement } & + & Glycerol & - \\
\hline \multicolumn{2}{|l|}{ Salinity range for growth } & $1 \sim 10 \%$ & & \\
\hline \multicolumn{2}{|c|}{$\mathrm{G}+\mathrm{C}$ content of DNA } & $42.3 \mathrm{~mol} \%$ & & \\
\hline \multirow{3}{*}{\multicolumn{2}{|c|}{ Production of isoprenoid quinones }} & Ubiquinone-8 (major) & & \\
\hline & & Ubiquinone-7 (minor) & & \\
\hline & & Ubiquinone-9 (minor) & & \\
\hline
\end{tabular}


culture broth (4.8 liters in total) was centrifuged, and the supernatant was discarded. Cells were suspended in $300 \mathrm{ml}$ of $95 \%$ aqueous ethanol and extracted with a cell disrupter. The extract was concentrated to a small volume of an aqueous solution, and the concentrate was extracted twice with $500 \mathrm{ml}$ of ethyl acetate, the final extract then being concentrated to dryness. The residue was applied on a silica gel column $(25 \mathrm{~mm} \times 8 \mathrm{~cm})$ and eluted with chloroform. The bioactive fraction was evaporated to give a residue, which was further purified by sizeexclusion HPLC (JAIGEL 1HF, Japan Analytical Industries, Tokyo; $20 \mathrm{~mm} \times 300 \mathrm{~mm}$ column, $3.0 \mathrm{ml} /$ minute flow rate), eluting with chloroform. Evaporation of the bioactive fraction afforded $2.4 \mathrm{mg}$ of korormicin as a colorless oil, the retention time for korormicin in this system being 10.2 minutes. $[\alpha]_{\mathrm{D}}^{26}-24.4^{\circ}(c 0.29, \mathrm{EtOH})$; IR (KBr) v: 3438, 2930, 2860, 1765, 1700, 1655, 1543, $1460,1381,1328,1205,1110,1054,996,948 \mathrm{~cm}^{-1}$; UV (EtOH) $\hat{\lambda}_{\max }(\log \varepsilon) 233 \mathrm{~nm}(4.80) .{ }^{1} \mathrm{H}$ - and ${ }^{13} \mathrm{C}-\mathrm{NMR}$ chemical shifts and observed HMBC correlations are shown in Table 2.

\section{Structural Determination}

Positive FAB-MS data for korormicin gave a pseu- domolecular ion at $m / z 434\left([\mathrm{M}+\mathrm{H}]^{+}\right)$. High resolution FAB-MS $\left(m / z\left([\mathrm{M}+\mathrm{H}]^{+}\right)\right.$: found, 434.2898; calcd., 434.2906) established the molecular formula as $\mathrm{C}_{25} \mathrm{H}_{39} \mathrm{NO}_{5}$ for korormicin. The IR spectrum suggested the presence of ester $\left(1765 \mathrm{~cm}^{-1}\right)$ and amide $(1655$, $1543 \mathrm{~cm}^{-1}$ ) groups.

${ }^{1} \mathrm{H}$ - and ${ }^{13} \mathrm{C}-\mathrm{NMR}$ data (Table 2) indicate that the korormicin molecule contained two carbonyl groups, one $s p^{2}$ tertiary carbon, one $s p^{3}$ tertiary carbon bonded to a hetero atom, five $s p^{2}$ methines, three oxymethines, ten methylenes, one singlet methyl, and two triplet methyl groups. The chemical shift data combined with the ${ }^{1} \mathrm{H}$ ${ }^{1} \mathrm{H}$ COSY, TOCSY and HMBC spectral data revealed the following four partial structural units in korormicin: (a) $s p^{2}$ methine C-4 $(\delta 133.9)$ and $s p^{3}$ tertiary carbon C-5 ( $\delta$ 87.2) bonded to a methyl and an ethyl groups and to an oxygen atom; (b) $s p^{2}$ tertiary carbon C-3 $(\delta$ 125.1), (c) C-2 carbonyl carbon ( $\delta 168.4)$; and (d) amide of a $\mathrm{C}-18$ carboxylic acid containing a secondary hydroxyl, a conjugated diene, and an epoxide. These four units comprised the complete molecular formula for korormicin. Connection of these four structural units elucidated by HMBC and NOE spectra is described in Figure 1. By 2D NMR, there was no long-range corre-

Table 2. ${ }^{1} \mathrm{H}$ - and ${ }^{13} \mathrm{C}-\mathrm{NMR}$ data for korormicin (in DMSO- $d_{6}$ ).

\begin{tabular}{|c|c|c|c|}
\hline Position & $\partial \mathrm{C}$ & $\partial \mathrm{H}$ & $\begin{array}{l}\text { HMBC correlation } \\
\text { (from } \mathrm{H} \text { to) }\end{array}$ \\
\hline 2 & $168.4(\mathrm{~s})$ & & \\
\hline 3 & $125.1(\mathrm{~s})$ & & \\
\hline 4 & $133.9(\mathrm{~d})$ & $7.26(1 \mathrm{H}, \mathrm{s})$ & C-2, C-5 \\
\hline 5 & $87.0(\mathrm{~s})$ & & \\
\hline 6 & $31.2(\mathrm{t})$ & $1.74(2 \mathrm{H}, \mathrm{q}, 7.3)$ & C-4, C-5, C-7, C-8 \\
\hline 7 & $8.0(q)$ & $0.74(3 \mathrm{H}, \mathrm{t}, 7.3)$ & $C-5, C-6$ \\
\hline 8 & $24.1(\mathrm{q})$ & $1.37(3 \mathrm{H}, \mathrm{s})$ & $\mathrm{C}-2, \mathrm{C}-5$ \\
\hline $\mathrm{N}-\mathrm{H}$ & & $9.83(1 \mathrm{H}, \mathrm{s})$ & $\mathrm{C}-2, \mathrm{C}-4, \mathrm{C}-\mathrm{I}^{\prime}$ \\
\hline $1^{\prime}$ & $170.1(\mathrm{~s})$ & & \\
\hline \multirow[t]{2}{*}{$2^{\prime}$} & $44.0(\mathrm{t})$ & $2.39(1 \mathrm{H}, \mathrm{dd}, 5.4,14.4)$ & $\mathrm{C}-1^{\prime}, \mathrm{C}-3^{\prime}, \mathrm{C}-4^{\prime}$ \\
\hline & & $2.59(1 \mathrm{H}, \mathrm{dd}, 8.1, \mathrm{I} 4.4)$ & \\
\hline $3^{\prime}$ & $63.0(\mathrm{~d})$ & $4.83(1 \mathrm{H}, \mathrm{ddd}, 5.4,8.1,9.0)$ & \\
\hline $3-\mathrm{OH}$ & & $5.09(1 \mathrm{H}, \mathrm{d}, 4.4)$ & \\
\hline 4 & 132.7 (d) & $5.30(1 \mathrm{H}, \mathrm{dd}, 9.0,10.9)$ & $\mathrm{C}-2^{\prime}, \mathrm{C}-6^{\prime}$ \\
\hline $5^{\prime}$ & $128.0(\mathrm{~d})$ & $5.92(1 \mathrm{H}, \mathrm{dd}, 10.9,11.2)$ & $\mathrm{C}-3^{\prime}, \mathrm{C}-6^{\prime}, \mathrm{C}-7^{\prime}$ \\
\hline $6^{\prime}$ & $127.6(d)$ & $6.46(1 \mathrm{H}, \mathrm{dd}, 11.2,15.1)$ & C- 5, C- 8 \\
\hline $7^{\prime}$ & $130.9(\mathrm{~d})$ & $5.70(1 \mathrm{H}, \mathrm{dt}, 6.8,15.1)$ & $\mathrm{C}-5^{\prime}, \mathrm{C}-8^{\prime}, \mathrm{C}-9^{\prime}$ \\
\hline $8^{\prime}$ & $30.9(\mathrm{t})$ & $2.26(2 \mathrm{H}, \mathrm{dd}, 5.9,6.8)$ & $\mathrm{C}-5^{\prime}, \mathrm{C}-6^{\prime}, \mathrm{C}-7^{\prime}, \mathrm{C}-9^{\prime}$ \\
\hline $9^{\prime}$ & $55.1(\mathrm{~d})$ & $2.90(1 \mathrm{H}, \mathrm{dt}, 4.2,5.9)$ & C- $8^{\prime}$ \\
\hline $10^{\prime}$ & $56.0(\mathrm{~d})$ & $2.87(1 \mathrm{H}, \mathrm{dt}, 4.2,6.1)$ & C- $8^{\prime}$ \\
\hline $11^{\prime}$ & $27.2(t)$ & $1.48(2 \mathrm{H}, \mathrm{m})$ & $\mathrm{C}-10^{\prime}, \mathrm{C}-12^{\prime}$ \\
\hline $12^{\prime}$ & $26.1(t)$ & $1.38(2 \mathrm{H}, \mathrm{m})$ & $\mathrm{C}-11^{\prime}$ \\
\hline $13^{\prime}$ & $28.92^{a}(t)$ & $1.2 \sim 1.4(2 \mathrm{H}, \mathrm{m})$ & \\
\hline $14^{\prime}$ & $28.89^{x}(t)$ & $1.2 \sim 1.4(2 \mathrm{H}, \mathrm{m})$ & \\
\hline $15^{\prime}$ & $28.6^{\mathrm{a}}(\mathrm{t})$ & $1.2 \sim 1.4(2 \mathrm{H}, \mathrm{m})$ & \\
\hline $16^{\prime}$ & $31.2(\mathrm{t})$ & $1.22(2 \mathrm{H}, \mathrm{m})$ & \\
\hline $17^{\prime}$ & $22.1(\mathrm{t})$ & $1.24(2 \mathrm{H}, \mathrm{m})$ & $C-16^{\prime}$ \\
\hline $18^{\prime}$ & $13.9(\mathrm{q})$ & $0.83(3 \mathrm{H}, \mathrm{t}, 7 . \mathrm{l})$ & $C-16^{\prime}, C-17^{\prime}$ \\
\hline
\end{tabular}

a Interchangeable. 
lation to $\mathrm{C}-3$, but among these four above-mentioned units, only $\mathrm{C}-3\left(\begin{array}{l}\delta \\ 125.1\end{array}\right)$ and $\mathrm{C}-4$ ( $(\delta$ 133.9) were considered as being $s p^{2}$ carbons; these two atoms were thus suggested to be directly bonded. Observations by HMBC from the amide proton to C-4 and NOE data between the amide proton and $\mathrm{H}-4$ indicated the amide nitrogen to be connected to $\mathrm{C}-4$ through $\mathrm{C}-3$. Long-range coupling correlation to $\mathrm{C}-2$ was observed from both the amide proton and $\mathrm{H}-4$, suggesting that $\mathrm{C}-2$ was situated

Fig. 1. Partial structural units of korormicin ( $a, b, c$ and $d)$ and selected $\mathrm{HMBC}$ and NOE correlations.

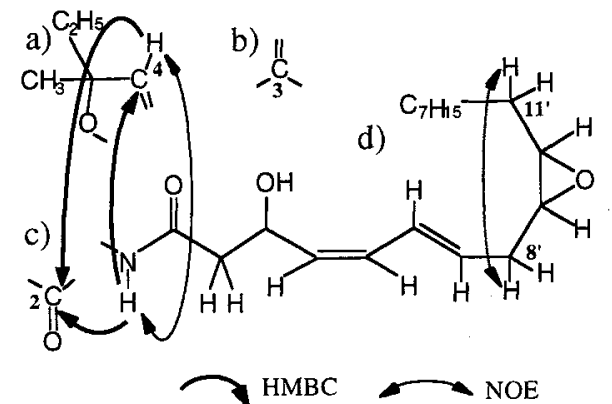

next to $\mathrm{C}-3$.

Consequently, C-2 would have been bound to $\mathrm{O}-1$, completing the whole planar structure of korormicin. With these connections, the four structural units constitute an $\alpha, \beta$-unsaturated $\gamma$-lactone, this premise being supported by the results of an IR absorption spectral analysis.

Coupling constants of 10.9 and $15.1 \mathrm{~Hz}$ for $J_{4^{\prime}, 5^{\prime}}$ and $J_{6}, 7$, , respectively, indicated the $Z$ - and $E$-configurations for each double bond. The NOESY correlation between methylene protons at the $8^{\prime}$ and $11^{\prime}$ positions and the vicinal coupling constant of $J_{9^{\prime}, 10^{\prime}}(4.2 \mathrm{~Hz})$ implied that the epoxide was of $c i s$ orientation.

The novel structure of korormicin was thus established

Fig. 2. Planar structure of korormicin.

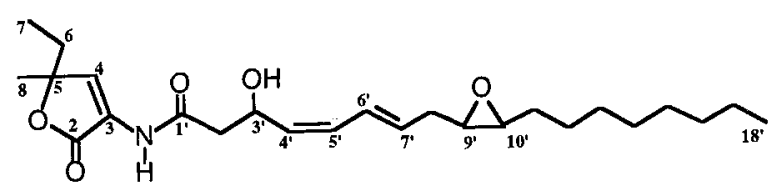

Table 3. Antibacterial activity of korormicin tested by the paper disk method.

i) Zone diameter against Gram-positive bacteria (mm).

\begin{tabular}{|c|c|c|c|c|c|c|c|}
\hline \multirow{2}{*}{ Strain } & \multirow{2}{*}{ Halophilicity } & \multicolumn{5}{|c|}{$\begin{array}{l}\text { Korormicin } \\
\quad(\mu \mathrm{g} / \mathrm{ml})\end{array}$} & \multirow{2}{*}{$\begin{array}{c}\begin{array}{c}\text { Penicillin G } \\
(\mu \mathrm{g} / \mathrm{ml})\end{array} \\
100\end{array}$} \\
\hline & & 1000 & 200 & 40 & 10 & 2 & \\
\hline Marinococcus halophilus IAM12844 & + & - & - & - & - & - & 42 \\
\hline Rhodococcus marinonascens IFO14363 & + & - & - & - & - & - & 50 \\
\hline Brevibacterium alkanolyticum IFOI 2323 & - & - & - & - & - & - & $\mathrm{w}^{\mathrm{a}}$ \\
\hline Brevibacterium linens JCM6894 & - & - & - & - & - & - & I1.5 \\
\hline Rhodococcus globerulus IFO14831 & - & - & - & - & - & - & 35 \\
\hline Rhodococcus erythropolis ATCC 12674 & - & - & - & - & - & - & 25.5 \\
\hline Staphylococcus aureus IFO12732 & - & - & - & - & - & - & 30 \\
\hline Bacillus subtilis IFO3134 & - & - & - & - & - & - & 27 \\
\hline
\end{tabular}

ii) Zone diameter against Gram-negative bacteria (mm).

\begin{tabular}{|c|c|c|c|c|c|c|c|}
\hline \multirow{2}{*}{ Strain } & \multirow{2}{*}{ Halophilicity } & \multicolumn{5}{|c|}{$\begin{array}{l}\text { Korormicin } \\
\quad(\mu \mathrm{g} / \mathrm{ml})\end{array}$} & \multirow{2}{*}{$\frac{\begin{array}{c}\text { Polymixin B } \\
(\mu \mathrm{g} / \mathrm{ml})\end{array}}{100}$} \\
\hline & & 1000 & 200 & 40 & 10 & 2 & \\
\hline Alteromonas macleodii ATCC27126 & + & 20 & 17 & 11 & - & - & 10 \\
\hline Pseudoalteromonas haloplanktis ATCC14393 & + & 22 & 18 & 15 & 13 & - & 18 \\
\hline Halomonas aquamarina ATCC 33127 & + & 17 & 14 & 12 & 9 & - & 9 \\
\hline Pseudomonas nautica ATCC27132 & + & 21 & 18 & 14 & 9 & - & 10 \\
\hline Shewanella putrefaciens ATCC 8071 & + & 26 & 19 & 9 & - & - & 12 \\
\hline Vibrio alginolyticus ATCC17749 & + & 17 & 15 & - & - & - & 8.5 \\
\hline Salinivibrio costicola ATCC 33508 & + & 36 & 30 & 24 & 16 & - & 12 \\
\hline Pelagiobacter variabilis $\mathrm{Ni}-2088$ & + & 15 & 13 & 9 & - & - & 9 \\
\hline Oceanospirillum beijerinckii ATCC $12754^{\mathrm{b}}$ & + & 32 & 25 & 18 & - & - & $\mathrm{w}$ \\
\hline Photobacterium phosphoreum IAM12085 & + & 22 & 17 & 14 & - & - & $\mathrm{w}$ \\
\hline Marinomonas communis ATCC27118 & + & 14 & 12 & - & - & - & 16 \\
\hline Escherichia coli IFO3301 & - & - & - & - & - & - & 12 \\
\hline
\end{tabular}

a Weak.

b $O$. beijerinckii subsp. beijerinckii ATCC12754. 
Table 4. MIC values for korormicin and a comparative standard against some terrestrial microorganisms.

\begin{tabular}{lcc}
\hline \multicolumn{1}{c}{ Strain } & $\begin{array}{c}\text { Korormicin } \\
(\mu \mathrm{g} / \mathrm{ml})\end{array}$ & $\begin{array}{c}\text { Polymixin B } \\
(\mu \mathrm{g} / \mathrm{ml})\end{array}$ \\
\hline Staphylococcus aureus ATCC6538P & $>83.3$ & $>83.3$ \\
Enterococcus hirae ATCC10541 & $>83.3$ & $>83.3$ \\
Bacillus subtilis $¥ 10707$ & $>83.3$ & 10.4 \\
Klebsiella pneumoniae ATCC10031 & $>83.3$ & 0.16 \\
Escherichia coli ATCC26 & $>83.3$ & 0.08 \\
Pseudomonas aeruginosa Bin H $\# \mathrm{I}$ & $>83.3$ & 2.6 \\
Proteus vulgaris ATCC6897 & $>83.3$ & $>83.3$ \\
Shigella sonnei ATCC9290 & $>83.3$ & 0.65 \\
Candida albicans ATCC10231 & $>83.3$ & $>83.3$ \\
\hline
\end{tabular}

to be an amide of a $\mathrm{C}-18$ unsaturated fatty acid derivative and a 4-hydroxyamino acid $\gamma$-lactone as described in Figure 2. The amino acid part of the molecule is structurally unique from the results of a literature survey.

\section{Biological Activity of Korormicin}

The antibacterial activity of korormicin as tested by the paper disk method is summarized in Table 3, and MIC values for some terrestrial microorganisms are shown in Table 4. The growth of all tested terrestrial microorganisms was not inhibited by korormicin. When it was applied to some marine bacteria which showed halophilic characteristics, an interesting result was obtained: korormicin was harmless to Gram-positive marine bacteria, whereas it had inhibitory activity against all of $11 \mathrm{Gram}$-negative types. The activity of korormicin was several times stronger than that of polymixin $B$ which was used as a reference. An enormous number of antibiotics have been studied, but no such antibacterial spectrum as that of korormicin has previously been reported. A few microorganisms living in seawater can survive in the absence of sodium chloride, but others live only in the presence of this salt. We are classifying the latter group of bacteria as marine bacteria based on their behavior against sodium chloride; however, the mechanistic background to the halophilic characteristics of marine bacteria is not known. Korormicin may be useful to clarify this mechanism and to classify marine bacteria, and will become a key compound for defining a marine bacterium.

\section{Acknowledgments}

The authors thank Prof. Kazuhide Yamasato of Tokyo University of Agriculture, Japan, for advice about the taxonomic studies. This work was performed as a part of The
Industrial Science and Technology Frontier Program supported by the New Energy and Industrial Technology Development Organization.

\section{References}

1) FAulkner, D. J.: Marine natural products. Nat. Prod. Rep. 14: $259 \sim 302,1997$

2) Mellado, E.; E. R. B. Moore, J. J. Nieto \& A. Ventosa: Analysis of $16 \mathrm{~S}$ rRNA gene sequences of Vibrio costicola strains: description of Salinivibrio costicola gen. nov., comb. nov. Int. J. Syst. Bacteriol. 46: 817 821, 1996

3) Takadera, T.; M. Nishijima, K. Yoshikawa, M. Araki \& H. SANO: Isolation and characterization of marine bacteria producing bioactive substances. Poster session of the 2nd Asia-Pacific Marine Biotechnology Conference and 3rd Asia-Pacific Conference on Algal Biotechnology, p. 97,1997

4) Cowan, S. T.: Cowan and Steel's manual for the identification of medical bacteria, 2nd ed., Cambridge University Press, London, 1974

5) Kaneko, T.; K. Katoh, M. Fujimoto, M. Kumagal, J. TamaOka \& Y. Katayama-Fujimura: Determination of the nucleotide composition of a deoxyribonucleic acid by high-performance liquid chromatography of its enzymatic hydrolysate: a review. J. Microbiol. Meth. 4: $229 \sim 240$, 1986

6) NishiJima, M.; M. Araki-SaKal \& H. SANO: Identification of isoprenoid quinones by Frit-FAB liquid chromatography-mass spectrometry for the chemotaxonomy of microorganisms. J. Microbiol. Meth. 28: 113 122, 1997

7) Baumann, P.; M. J. Gauthier \& L. Baumann: Genus Alteromonas Baumann, Baumann, Mandel and Allen 1972. In BERGEY's manual of systematic bacteriology. $E d$., J. G. HOLT \& N. R. KRIEG, pp. $343 \sim 352$, Williams \& Wilkins, Baltimore, 1984

8) Gauthier, G.; M. Gauthier \& R. Christen: Phylogenetic analysis of the genera Alteromonas, Shewanella, and Moritella using genes coding for small-subunit rRNA sequences and division of the genus Alteromonas into two genera, Alteromonas (Emended) and Pseudoalteromonas gen. nov., and proposal of twelve new species combinations. Int. J. Syst. Bacteriol. 45: $755 \sim 761,1995$ 